\title{
TELA DE POLIPROPILENO: ESTUDO DO EFEITO DE ESTERILIZAÇÃO NA ESTRUTURA EM FRAGMENTOS DE TELA PARA REUTILIZAÇÃO EM CIRURGIA DE HÉRNIA
}

\author{
POLYPROPYLENE MESH: STUDY OF THE EFFECT OF STERILIZATION IN THE \\ STRUCTURE OF A MESH FRAGMENT REUSED IN HERNIA SURGERY
}

\author{
Sidney Moreno Gil, TCBC-SP¹ ; Wagner Polito² ; Cláudio Penido Campos Júnior³; \\ Bruno Ziade Gil, $\mathrm{AsCBC}^{4}$; Leandro de Moura Centurion, $\mathrm{AsCBC}^{4}$; Luiz Fernando Dias Rodrigues, $\mathrm{AsCBC}^{5}$
}

\begin{abstract}
RESUMO: Objetivo: Estudar os efeitos de múltiplas esterilizações em formaldeido em baixa temperatura, na estrutura molecular (físico-químico) e no desenvolvimento de microorganismos na tela de polipropileno, utilizada na correção cirúrgica das diferentes hérnias da parede abdominal. Método: Utilizou-se tela de polipropileno plana padrão (Ethicon), de $15 \mathrm{cmx} 15 \mathrm{~cm}$, a qual foi recortada em fragmentos iguais de $2 \mathrm{cmx} 1 \mathrm{~cm}$, após múltiplas esterilizações. Foram denominadas amostras $\mathrm{A}$ (controle), $\mathrm{A}_{1}$ (uma esterilização) e $\mathrm{A}_{3}$ (três esterilizações); e B (controle), $\mathrm{B}_{1}$ (uma esterilização), $\mathrm{B}_{2}$ (duas esterilizações), $\mathrm{B}_{3}$ (três esterilizações), $\mathrm{B}_{4}$ (quatro esterilizações) $\mathrm{e}_{5}$ (cinco esterilizações). As amostras $\mathrm{A}$ foram submetidas à análise por Espectroscopia no Infravermelho (FTIR) e Microscopia Eletrônica por Varredura (MEV) e as amostras B foram semeadas em meios de "Brain Heart Infusion" (BHI), Ágar Sabouraud Dextrosado e Ágar Chocolate (hemácias de carneiro a 5\%). Resultados: A análise comparativa das amostras $\mathrm{A}_{2} \mathrm{~A}_{1}$ e $\mathrm{A}_{3}$ revela suficientes evidências experimentais de que sejam idênticas, do ponto de vista da composição, mantendo, inclusive, os mesmos padrões de porosidade. Nas amostras $\mathrm{B}_{1}, \mathrm{~B}_{2}, \mathrm{~B}_{3}, \mathrm{~B}_{4}$ e $\mathrm{B}_{5}$ não houve desenvolvimento de microorganismos nos fragmentos submetidos até cinco esterilizações. Conclusão: A tela de polipropileno não sofre alterações na sua estrutura molecular, podendo ser submetida até cinco esterilizações, sem que ocorra o desenvolvimento de microorganismos nas amostras (Rev. Col. Bras. Cir. 2005; 32(4): 188-191).
\end{abstract}

Descritores: Telas cirúrgicas; Esterilização; Hérnias.

\section{INTRODUÇÃO}

Reduzir a recorrência na cirurgia da hérnia tornou-se um desafio ${ }^{1}$. A busca por próteses para corrigir os defeitos anatômicos iniciou-se com Phelps, em 1894, tendo ele utilizado pela primeira vez "tela" de fios de prata para reforço do canal inguinal ${ }^{2}$. Outras telas metálicas, como de Tântalo e fios de aço inoxidável, foram utilizadas.

As telas metálicas deram lugar às não metálicas, com melhor flexibilidade e modelagem, entre as quais podemos citar as telas de fortisan, polivinil, "nylon", silicone, téflon, fibra de carbono, poliéster, polipropileno, politetrafluoroetileno (PTFE) e ácido poliglicólico (Déxon). As mais utilizadas são as de polipropileno, pura ou mista ${ }^{3}$. Em nosso serviço utilizamos as telas de polipropileno.

O objetivo deste estudo foi avaliar os efeitos de múltiplas esterilizações com formaldeido em baixa temperatura na estrutura da manta do polímero (polipropileno) por Espectroscopia no Infravermelho e Microscopia Eletrônica por Varredura, assim como, observar a ocorrência de possível desenvolvimento de microorganismos nestas telas ${ }^{4-6}$.

\section{MÉTODO}

Foi utilizada tela plana de polipropileno $15 \mathrm{~cm} \times 15 \mathrm{~cm}$, manipulada sob técnica estéril em ambiente cirúrgico, recortando-se duas amostras A e B, de tamanhos idênticos de $2 \mathrm{~cm} \times 1 \mathrm{~cm}$. A tela residual foi submetida à esterilização com subseqüente recorte de amostra $\mathrm{A}_{1}$ e $\mathrm{B}_{1}$, de mesma medida. Em etapa sequiencial, a tela residual foi exposta ao segundo, terceiro, quarto e quinto processos de esterilização, sendo colhida amostra $B_{2}$ no segundo, $A_{3}$ e $B_{3}$ no terceiro, $B_{4}$ no quarto e $\mathrm{B}_{5}$ no quinto processamento. Desta maneira, foram colhidas amostras A, $\mathrm{A}_{1}$ e $\mathrm{A}_{3}$ e B, B, $\mathrm{B}_{2}, \mathrm{~B}_{3}, \mathrm{~B}_{4}, \mathrm{~B}_{5}$ para os estudos propostos.

As amostras $\mathrm{A}, \mathrm{A}_{1}$ e $\mathrm{A}_{3}$ foram submetidas à análise por Espectroscopia no Infravermelho (FTIR), que é uma técnica bem trabalhada e bem resolvida para análises de substâncias ${ }^{4}$. Um espectro de infravermelho representa a imagem física da radiação absorvida ou transmitida por uma amostra, que pode ser armazenada digitalmente e mostra picos de absorção que correspondem à freqüência de vibrações entre ligações de átomos que constituem as moléculas dos materiais. Como cada material diferente tem uma única

1. Diretor da Comissão de Controle de Infecção Hospitalar (CCIH), e Presidente da Comissão de Residência Médica (COREME) do Hospital São Domingos - Catanduva - SP.

2. Professor Doutor do Instituto de Química da USP - São Carlos - SP.

3. Médico Infectologista da CCIH do Hospital São Domingos - Catanduva - SP

4. Médico Residente 2 de Cirurgia Geral do Hospital São Domingos - Catanduva - SP.

5. Médico Residente 3 de Cirurgia Geral do Hospital São Domingos - Catanduva - SP.

Recebido em 10/01/2005

Aceito para publicação em 10/05/2005

Conflito de interesse: nenhum

Fonte de financiamento: nenhuma

Trabalho realizado no Hospital São Domingos - Catanduva - SP, Instituto de Química da USP - São Carlos - SP e Laboratório de Microbiologia do Hospital das Clínicas de Ribeirão Preto - SP. 


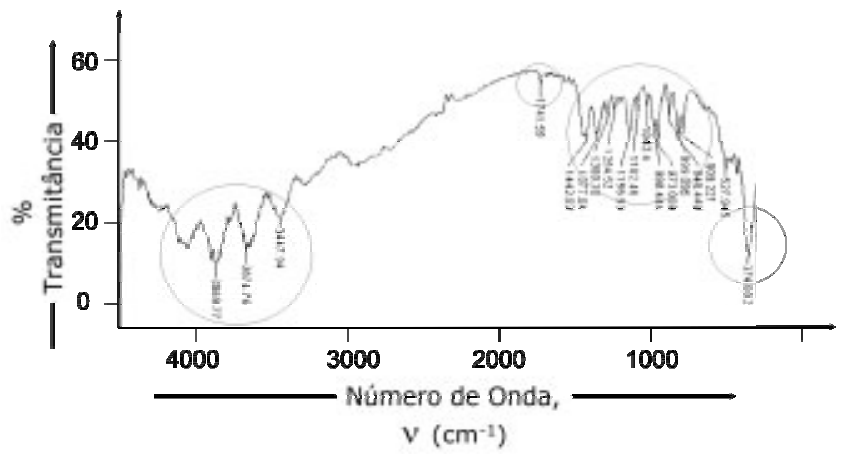

Gráfico 1 - Espectroscopia de Infravermelho da amostra de referência (nova, sem ser submetida a nenhum tratamento de esterilização).

combinação possível de átomos, dois compostos diferentes não podem produzir, exatamente, o mesmo tipo de espectro infravermelho. Portanto, a Espectroscopia de Infravermelho permite análise qualitativa de cada componente diferente de cada material, assim como pelo tamanho dos picos nos espectros há uma indicação direta da quantidade do material presente.

Para os estudos desenvolvidos foram preparadas amostras de manta de polipropileno nas seguintes condições:

- umidade relativa de $38,0 \%$ a $51,0 \%$

- temperatura entre $22^{\circ} \mathrm{C}$ a $27^{\circ} \mathrm{C}$

Utilizaram-se as bandas espectrais obtidas no gráfico "\% de transmitância em função do número de ondas $\left(\mathrm{cm}^{-1}\right)$ ", comparando-se os espectros das amostras.

A outra avaliação ocorreu por Microscopia Eletrônica de Varredura (MEV), que entre os procedimentos de visualização de amostras por meio de amplificação da imagem, com revelação de detalhes submicroscópicos, é a técnica com melhor relação custo/benefício. Foram obtidas ampliações de 32, 50, 100, 200, 300, 500, 1.000, 2.000, $3.000,5.000,10.000$ vezes, após revestimento de ouro. As análises foram realizadas no Instituto de Química - USP São Carlos.

As amostras $\mathrm{B}\left(\mathrm{B}_{1}\right.$ a $\left.\mathrm{B}_{5}\right)$, colhidas sob técnica estéril, foram acondicionadas em frascos estéreis e secos, destinados ao armazenamento de material biológico para cultura e, em seguida, enviados aos laboratórios de microbiologia do Hospital São Domingos e do Hospital das Clínicas da Faculdade de Medicina de Ribeirão Preto - USP (fragmento 5). Os materiais foram semeados em meios de "Brain Heart Infusion" (BHI), Ágar Sabouraud Dextrosado e Ágar Chocolate (hemácias de carneiro a 5\%). Foram mantidas sob temperatura variável entre $35^{\circ} \mathrm{C}$ e $37^{\circ} \mathrm{C}$, durante 48 horas. A positividade seria detectada na presença de colônias ou frente à turvação dos meios.

\section{RESULTADOS}

As amostras $\mathrm{A}, \mathrm{A}_{1}$ e $\mathrm{A}_{3}$ submetidas à análise por Espectroscopia no Infravermelho (FTIR), que possibilitou estudar por caracterização das bandas espectrais, a estrutura do polímero qualitativa e quantitativamente, revelaram que todas as três amostras têm sinais analíticos muito semelhantes ${ }^{4}$. Não

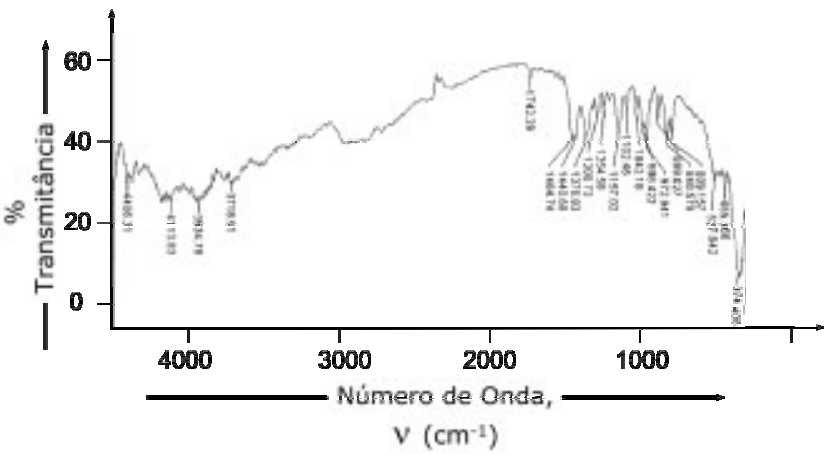

Gráfico 2 - Espectroscopia de Infravermelho da amostra 3 (com três tratamentos de esterilização).

houve alterações nas estruturas moleculares, após serem submetidas a até três esterilizações no formaldeido em baixa temperatura, mantendo-se o mesmo padrão de comprimento de ondas e transmitância (Gráficos 1 e 2). As mesmas amostras foram submetidas, após tratamento com ouro, à análise por Microscopia Eletrônica de Varredura (MEV), excelente método de informações visuais, com alcance para se inferir sobre morfologia e alterações relevantes do ponto de vista estrutural. As fotos receberam ampliações de 32 a 10.000 vezes permitindo a análise estrutural do polímero (Figuras 1 e 2).

A observação das fotos em todas as suas ampliações revela que:

- Não se observam quaisquer alterações nas amostras, que possam ser consideradas absolutamente idênticas entre si; tampouco se observam alterações morfológicas que possam comprometer a estrutura da malha de polipropileno, mantendo a área média dos poros $\left(0,863 \mathrm{~mm}^{2}\right)$.

- Nas três amostras há uma espécie de incrustação que se torna visível apenas com magnificação de 200 vezes. Aparentemente pode ser uma exsudação orgânica. É muito comum, em polímeros, o uso de plastificantes externos que, ao longo do tempo, podem se movimentar do interior para a sua superfície. São esses plastificantes que permitem a flexibilidade da tela e sua aplicabilidade nas diversas indicações cirúrgicas.

As amostras B, $\mathrm{B}_{1}, \mathrm{~B}_{2}, \mathrm{~B}_{3}, \mathrm{~B}_{4}, \mathrm{~B}_{5}$, semeadas nos meios já descritos com leitura em 48 horas, não revelaram crescimento de colônias bacterianas ou outro tipo de microorganismos. O processo de reesterilização a que foram submetidos os fragmentos da tela revelou-se eficiente, mantendo o biomaterial em condições assépticas.

\section{DISCUSSÃO}

A procura por materiais sintéticos para diminuir as recidivas nas correções das hérnias da parede abdominal observadas com as técnicas convencionais ${ }^{7}$, culminou com a introdução por Usher ${ }^{8}$ da tela de polipropileno. Desde então, as estatísticas de recidiva das hérnias de parede abdominal diminuíram expressivamente permanecendo menor que $1 \%$ com técnica laparoscópica ou convencional.

Dados americanos de 2003 mostram que em 93\% das cirurgias de hérnias inguinais foi utilizada tela de polipropileno 


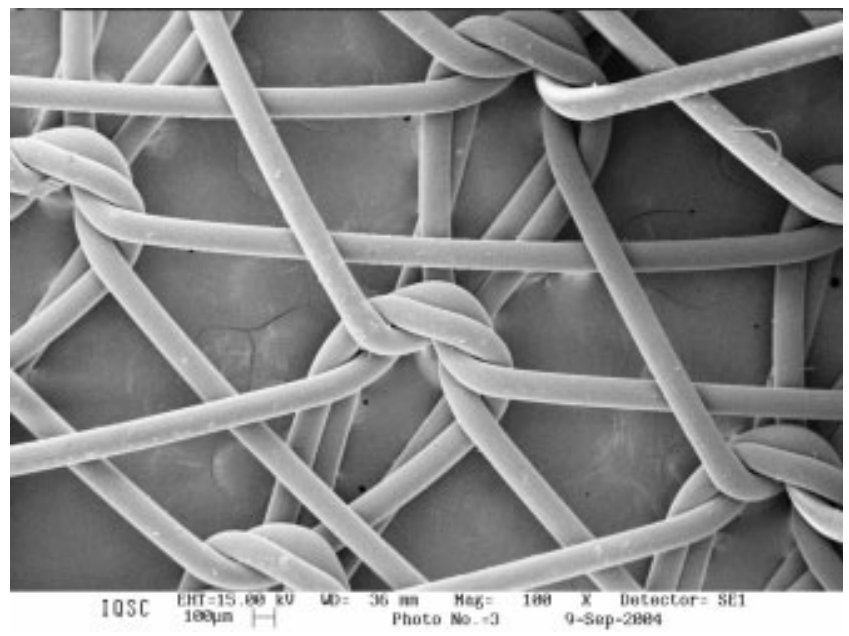

Figura 1 - Foto da amostra A (controle, com aumento de X100).

e em apenas 7\% empregaram-se técnicas de correção tecidotecido ${ }^{9}$. No Brasil inexistem dados relativos às técnicas que empregam próteses e em nosso hospital, um levantamento dos últimos cinco anos mostra o emprego de tela em $70 \%$ das cirurgias. Os outros $30 \%$ das hérnias inguinais foram tratados por diferentes técnicas ${ }^{10}$.

Em nosso meio, atribuímos menor porcentagem na indicação da tela na herniorrafia principalmente a dois fatores:

- custo da tela, acrescido, muitas vezes da restrição por parte dos planos de saúde e sistema público de saúde em utilizá-la;

- proibição pela Agência Nacional de Vigilância Sanitária (ANVISA) à reutilização de recortes da tela original, após reesterilização ${ }^{11}$.

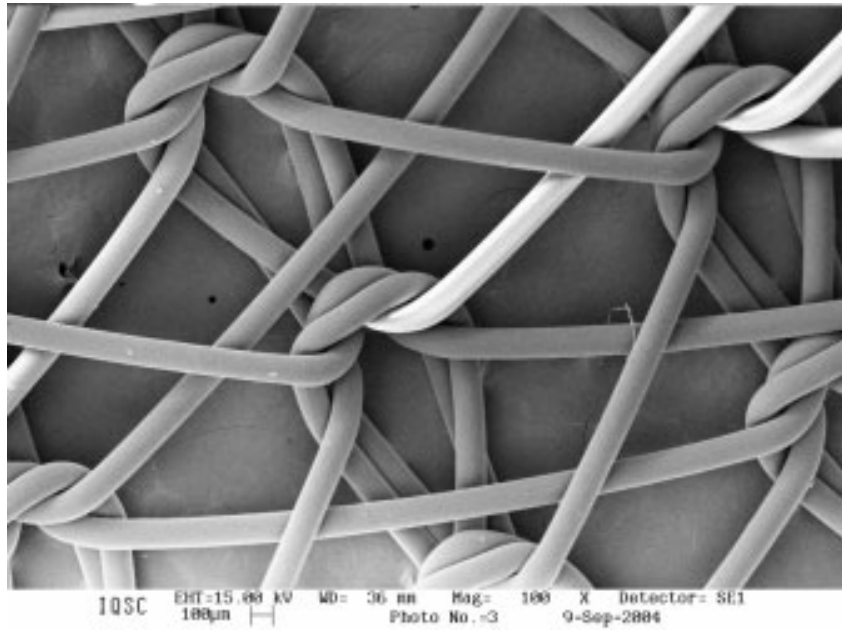

Figura 2 - Foto da Amostra A3 (com três tratamentos de esterilização).

Os estudos realizados nas amostras A e B, pelos métodos já descritos, nos asseguram a possibilidade de ampliar a utilização dos recortes de tela após re-esterilização, quando preparados em ambiente cirúrgico. Uma tela plana, $15 \mathrm{cmx} 15 \mathrm{~cm}$, submetida a recorte e moldagem adequados poderia ser utilizada com segurança em três ou quatro cirurgias, diminuindo o custo final, beneficiando um número maior de pacientes e, melhorando os resultados quanto à recidiva das hérnias.

\section{AGRADECIMENTOS}

Rosa Helena Ampreno Romanella Gironi microbiologista encarregada do Laboratório de Microbiologia do Hospital das Clínicas da Faculdade de Medicina de Ribeirão Preto - USP.

\begin{abstract}
Background: Our objective is to study the effects of multiples formaldehyde sterilizations at low temperature in the molecular structure (physical-chemical) as well as on microorganism growth in a polypropylene mesh used for the surgical correction of different hernias of the abdominal wall. Methods: We used an even mesh (Ethicon) standard $15 \mathrm{~cm} x 15 \mathrm{~cm}$, cutted into small $2 \mathrm{~cm} x 1 \mathrm{~cm}$ pieces after multiples sterilizations. They were named samples $A$ (control), $A_{1}$ (one sterilization), $A_{3}$ (three sterilizations) and $B$ (control), $B_{1}$ (one sterilization) $B_{2}$ (two sterilizations), $B_{3}$ (three sterilizations), $B_{4}$ (four sterilizations), $B_{5}$ (five sterilizations).The meshes A were analysed by Spectroscopy in Infrared (FTIR) and Microscopy Electronic by Sweepings(MEV), and meshes B were incubated within Brain Heart Infusion (BHI), Agar Saboraud Dextrose and Agar Chocolate (red sheep cells at 5\%). Results: The sample comparative analyses $A, A_{1}, A_{3}$, showed to be identical according to the composition including the same pattern of porosity. Concerning samples $B(1,2,3,4$ and 5$)$ no microorganism was found on the parts under up to five sterilizations. Conclusions: The polypropylene mesh is not altered as a molecular structure, and it can be sterilized up to five times with no chance for microorganisms on the samples.
\end{abstract}

Key words: Surgical mesh; Sterilization; Hernia.

\section{REFERÊNCIAS}

1. Read RC. Desenvolvimento da herniorrafia inguinal. Surg Clin North Am. 1984;(2):197-207.

2. De Debord JR. The historical development of prosthetics in hernia surgery - Surg Clin North Am. 1998;78(6):973-1006.
3. Scales JT. Discussion on metals and synthetic materials in relation to soft tissue: Tissue reaction to synthetic materials. Proc Roy Soc Med. 1953; 46:647.

4. Kincaid JR. Infrared and raman spectroscopy. In: Cristian GD, O'Reilly JE, editors. Instrumental analysis. 2nd ed. Boston: Allyn \& Bacon, Inc; 1986. p. 212-246 
5. Deysine M. Pathophysiology, prevention, and management of prosthetic infections in hernia surgery. Surg Clin North Am. 1998; 78(6):1105-15.

6. Stephenson BM. Complications of open groin hernia repairs Surg Clin North Am. 2003;83(5):1255-78.

7. Mittelstaedt WEM, Rodrigues AJ, Duprat J, et al. Tratamento das hérnias inguinais: Bassini ainda atual? Estudo randomizado, prospectivo e comparativo entre três técnicas operatórias: Bassini, Shouldice, McVay. Rev. Assoc Med Brasil. 1999;45(2):105-14

8. Usher FC. Hernia repair with knitted polypropylene mesh. Surg Gynecol Obstet. 1963;117:239-40.1

9. Rutkow IM. Demographic and socioeconomic aspects of hernia repair in the United States in 2003. Surg Clin North Am. 2003;83(5):1045-51.
10. Vinháes JC. Paredes Abdominais - Hérnias. In: Vinháes JC. Clínica e terapêutica cirúrgicas. $2^{\mathrm{a}}$ Edição. Rio de Janeiro: Guanabara Koogan; 2003. p. 544-568.

11. Consultas Públicas [database on the Internet]. ANVISA: Guia "Lista de Produtos Médico-Hospitalares de Uso Único"; 2004 - [citado 2004 março 19] Consulta Pública n 17. Available from: http://www4.anvisa.gov.br/base/visadoc/CP/CP[6781-10].PDF

Endereço para correspondência:

Sidney Moreno Gil

Rua Cuiabá, 413 - Centro

15800-220 - Catanduva - SP

E-mail: sgil@ skynew.com.br 